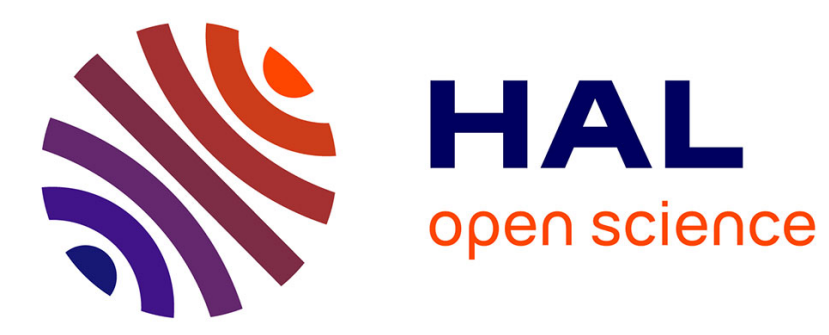

\title{
Influence of germanium on the viscosity of liquid selenium
}

G. Chaussemy, J. Fornazero, A. Laugier

\section{To cite this version:}

G. Chaussemy, J. Fornazero, A. Laugier. Influence of germanium on the viscosity of liquid selenium. Journal de Physique Lettres, 1976, 37 (11), pp.283-285. 10.1051/jphyslet:019760037011028300 jpa00231293

\section{HAL Id: jpa-00231293 https://hal.science/jpa-00231293}

Submitted on 1 Jan 1976

HAL is a multi-disciplinary open access archive for the deposit and dissemination of scientific research documents, whether they are published or not. The documents may come from teaching and research institutions in France or abroad, or from public or private research centers.
L'archive ouverte pluridisciplinaire HAL, est destinée au dépôt et à la diffusion de documents scientifiques de niveau recherche, publiés ou non, émanant des établissements d'enseignement et de recherche français ou étrangers, des laboratoires publics ou privés. 


\title{
INFLUENCE OF GERMANIUM ON THE VISCOSITY OF LIQUID SELENIUM (*)
}

\author{
G. CHAUSSEMY, J. FORNAZERO
}

Laboratoire de Physique Electronique, Université Lyon I, France

\section{A. LAUGIER}

Laboratoire de Physique de la Matière $(* *)$

Institut National des Sciences Appliquées de Lyon, 69621 Villeurbanne, France

(Reçu le 22 juin 1976, accepté le 5 août 1976)

\begin{abstract}
Résumé. - La viscosité cinématique des solutions liquides $\mathrm{Ge}_{x} \mathrm{Se}_{1-x}$ est étudiée dans les limites $300-600^{\circ} \mathrm{C}$ pour $x$ inférieur à 0,1 . Elle augmente fortement avec $x$ jusqu'à l'eutectique $(x=0,08)$. Ceci est expliqué par le concept de liquide associé de Jordan relié au modèle de croisement de chaînes. Pour $x<0,08$, la variation avec la température est semblable à celle du Sélénium pur. Un modèle de polymère décrit bien ce comportement dans le cadre du formalisme du volume libre.

Abstract. - The kinematic viscosity of Se rich $\mathrm{Ge}_{x} \mathrm{Se}_{1-x}$ liquids is investigated in the range $300-600{ }^{\circ} \mathrm{C}$ for $0<x<0.1$. It increases strongly versus $x$. However the behaviour remains Selenium like up to the eutectic $(x=0.08)$. A polymer model, in the free volume formalism, gives a good description of the temperature variation. The chain-crossing effect of $\mathrm{Ge}$ in Se explains the $x$-variation in relation to the polymer type association (Jordan's model) in the liquid solution.
\end{abstract}

1. Introduction. - The influence of the so-called branching elements $\mathrm{As}$ and $\mathrm{Bi}$ on the structure of liquid and amorphous Se is known [1]. The effect of addition of these elements is visualized as a breaking of $\mathrm{Se}_{8}$ rings and the interconnection of chains. $\mathrm{A}$ similar behaviour is assumed also for Ge. Furthermore the thermodynamic properties of the liquid solutions involving $\mathrm{Se}$ with elements of group II and IV (namely Ge-Se), can be well described by the regular associated solution model of Jordan $[2,3]$. In this model a polymer type association is postulated. The viscous flow is very sensitive to changes in bonding and atomic structure. So, a strong increase of viscosity is expected as the Ge concentration $(x)$ in liquid $\mathrm{Se}$ is increased.

The phase diagram of the Ge-Se system, compiled from the most recent papers is given in reference [4]. It differs from the one given by Glazov and Situlina [5]. More particularly, a liquid immiscibility appears between $x=1(\mathrm{Ge})$ and $x=0.5(\mathrm{GeSe})$ and a eutectic exists near pure Se : $218^{\circ} \mathrm{C}, x=0.08$. As remarked by Glazov et al. [6] important changes in the intermolecular interaction arise near eutectics. So, we have limited this work to the composition range $0-0.10$,

(*) Work supported by the C.N.R.S. (ATP).

(**) Equipe de recherche associée au C.N.R.S. since the analysis of the results for $x$ larger than 0.10 is more complicated due to the expected presence of $\mathrm{GeSe}$ and $\mathrm{GeSe}_{2}$ molecular species in the liquid. This composition range was not considered in the previous work on the viscosity of Ge-Se system [5]. Furthermore in the high temperature range of measurements of reference [5] $\left(900-1050^{\circ} \mathrm{C}\right)$ dissociation occurs and the covalent bonding in the liquid disappears. Consequently, the behaviour described in this work cannot be observed. We are interested in the temperature range near the liquidus line $300-600{ }^{\circ} \mathrm{C}$ where the expected association in the liquid is strong.

2. Experimental method. - The viscosity measurements were carried out using a Meyer-Schvidkovskii torsional oscillating cup viscometer $[6,7]$. The kinematic viscosity $v$ is deduced from the logarithmic decrements of damped oscillations. The liquid is contained in a sealed quartz ampoule. The relative precision can be estimated at $5 \%$ in the range of measurements. The temperature is stabilized with an accuracy of $\pm 1^{\circ} \mathrm{C}$. Selenium and Germanium were high purity materials $(99.999 \%)$.

3. Results. - The viscosity of Ge-Se melts is plotted versus reciprocal temperature, with the $\mathrm{Ge}$ concentration $x$ as a parameter. For pure Selenium 
our data agree with previous results $[6,8-11]$ the viscosity increases quickly versus $x$ except near the eutectic point $(x=0.8,0.10)$. The curves are nearly parallel to the pure Se one, suggesting similar nature of these liquids. As for pure Se, the apparent activation energy of the viscous flow decreases with rising temperature. The larger is $x$ the more it depends on temperature.

4. Analysis and discussion. - The kinematic viscosity $v$ is related to the dynamic viscosity $\eta$ by : $\eta=v d$, where $d$ is the density. In the compositiontemperature range of interest the variations of $d$ versus $x$ and $T$ are linear [12] : for $x=0$ Ruska [12] gives $d=3.788$ and $3.572 \mathrm{~g} . \mathrm{cm}^{-3}$ at $T=400$ and $600{ }^{\circ} \mathrm{C}$, respectively. These data agree with reference [11]. For $x=0.2, d=4.072$ and 3.907 at $T=400$ and $600{ }^{\circ} \mathrm{C}$ respectively.

For pure Se and Se-Te alloys Rialland and Perron [11] observed a variation of the apparent activation energy $E$ deduced from an Arrhenius plot for the dynamic viscosity. $E$ increases with decreasing $T$. The viscosity decreases when the $\mathrm{Te}$ concentration increases. Te breaks the Se chains. Using the free volume formalism these authors have got a good description for the $T$ dependence of $\eta$. Because of the similar temperature behaviour for pure Se and Se rich Se-Ge alloys, it is convenient to use the same model. Then :

$$
v=\frac{A}{d} T^{1 / 2} N \exp \frac{\pi}{12} \frac{a^{3}}{\alpha V\left(T-T_{0}\right)} .
$$

$A$ is related to the segmental friction factor, $\alpha$ is the coefficient of thermal expansion, $V$ the mean molecular volume. $T_{0}$ is the temperature at which the free volume disappears, taken equal to the glass transition temperature $T_{\mathrm{g}} . a$ is the first nearest neighbour distance. $N$ is the average chain length :

$$
N=N_{0} \exp \frac{E}{k T} .
$$

So, combining (1)-(2) the following equation is used :

$$
v=\frac{B}{d} T^{1 / 2} \exp \left[\frac{E}{k T}+\frac{\pi}{12} \frac{a^{3}}{\alpha V\left(T-T_{\mathrm{g}}\right)}\right]
$$

where $E$ and $B$ are adjustable parameters.

$T_{\mathrm{g}}$ is known [13, 14]. It varies linearly from $30^{\circ} \mathrm{C}$ $(x=0)$ to $100^{\circ} \mathrm{C}(x=0.1)$. The values for $a$ are not directly determined, except for pure Selenium $(a=2.3 \AA)[15]$. However, in corresponding amorphous materials no significant change arises for $a$ [16]. We have fitted the viscosity data with the Se $a$ value. The calculated viscosities are shown by the solid lines of the figure with the values of $E$ given in table I. The agreement with the experimental data is good. For pure Se, we obtain the same value as reference [11]. The energy $E$ decreases with increasing Ge concentration up to the eutectic and increases after.

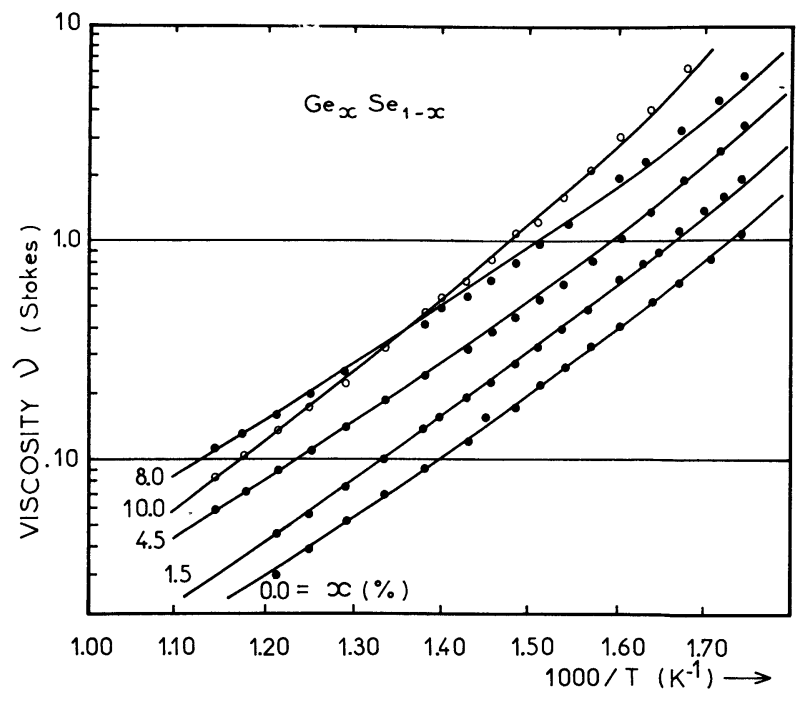

FIGURE. - Kinematic viscosity for $\mathrm{Ge}_{x} \mathrm{Se}_{1-x}$ liquid alloys near pur Se. Note the change of behaviour over the eutectic $(x=8 \%)$.

TABLE I

Activation energy of the viscous flow for $\mathrm{Ge}_{x} \mathrm{Se}_{1-x}$ liquid alloys

$\begin{array}{llllll}x(\%) & 0 & 1.5 & 4.5 & 8 & 10 \\ E(\mathrm{eV}) & 0.55 & 0.53 & 0.50 & 0.40 & 0.60 \\ ( \pm 0.05) & & & & & \end{array}$

In this analysis no rings were considered in liquid Se. If they exist, their number decreases when $\mathrm{Ge}$ atoms are introduced. Then, the equilibrium ringchain should be considered and could explain the variation of $E$. However, the existence of rings in liquid $\mathrm{Se}$ is not firmly established and one cannot draw conclusions from viscosity data alone.

Parameter $B$, in eq. (3), involves both $A$ and $N_{0}$, so that we cannot deduce the chain length from the present analysis. The increase of the viscosity with $x$ can be due to the chain elongation and/or to the increase of the interaction within the chains. However, in the Ge-Se liquid solutions, no Ge-Ge bond exists if the association is strong. This hypothesis is supported by the two following remarks :

i) The existence of liquid immiscibility in the metal $(\mathrm{Ge})$ part of the liquidus as discussed by Jordan [2] and Hume-Rothery [17].

ii) The following experiment on amorphous Ge-Se alloys :

- Raman scattering and optical absorption of Tronc et al. [4],

- Thermal conductivity and sound velocity measurements of Stourac et al. [18].

These observations suggest that Germanium enters a Selenium chain substitutionally and acts as a crosslinking element. Thus, when $x$ increases the weak Van der Waals force between the chains gradually becomes 
negligible in comparison to the strong covalent bond Ge-Se. This conclusion is supported also by the data near the eutectic. The activation energy $E$ quickly increases. A singularity can be observed at high temperature on an isotherm viscosity versus $x$ plot. This behaviour suggests a modification in the bonding force $F$ between atoms. Near Se we have

$$
F_{\mathrm{Se} \mathrm{Se}}>F_{\mathrm{Ge} \mathrm{Se}}>F_{\mathrm{Ge} \mathrm{Ge}} \text {. }
$$

At the eutectic, $F_{\mathrm{Ge}-\mathrm{Se}}$ becomes larger than $F_{\mathrm{Se}-\mathrm{Se}}$. The behaviour of the liquid is Selenium like up to $x=0.08$ only. It is interesting to note that this increment for $F_{\mathrm{Ge}-\mathrm{Se}}$ is closely related to the increasing of the stability of the corresponding glasses [14].

Acknowledgements. - The authors thank J. Ruska and J. C. Perron for the communication of their respective data before publication.

\section{References}

[1] MotT, N. F., DAvIS, E. A., Electronic processes in non-crystalline materials (Clarendon Press) 1971 ch. 10.

[2] Jordan, A. S., Metall Trans. 1 (1970) 239.

[3] Laugier, A., Revue Phys. Appl. 8 (1973) 259.

[4] Tronc, P., Bensoussan, M., Brenac, A., Sebenne, C., Phys. Rev. B 8 (1973) 5947.

[5] Glazov, V. M., Situlina, O. V., Dok. Akad. Nauk. SSSR 187 (1969) 799.

[6] Glazov, V. M., Chizhevskaya, S. N., Glagoleva, N. N., Liquid semiconductors (Plenum Press, N. Y.) 1969.

[7] WitTenberg, L. J., Techniques of Metals Research (Interscience) R. A. Rapp Editeur, (1970) 2, chap. 7 A, vol. IV.

[8] Hamada, S., Yoshida, N., ShiraI, T., Bull. Chem. Soc. Japan 42 (1969) 1025.

[9] Cukierman, M., Uhlmann, D. R., J. Non-Cryst. Solids 12 (1973) 199.
[10] LaBIB, H. A., Thèse, Lyon (1974).

[11] Rialland, J. F., Perron, J. C., 6th Int. Conf. on Amorphous and Liquid Semiconductors, Leningrad (Nov. 1975) to be published.

[12] RUSKA, J., to be published.

[13] Dembovski, S. A., Vinogradova, G. Z., Pashinkin, A. S., Russ. J. Inorg. Chem. 10 (1965) 903.

[14] Azoulay, R., Thibierge, H., BrenaC A., J. non-cryst. Solids 18 (1975) 33.

[15] Tourand, G., J. Physique 34 (1973) 937.

[16] FawCett, R. W., WaGner, C. N. J., Cargill, J. non-Cryst. Solids 8 (1972) 369.

[17] Hume-Rothery, W., ANderson, E., Phil. Mag. 8 (1960) 383.

[18] Stourac, L., Vasho, A., Musil, C., Storba, F., Czech. J. Phys. B 18 (1968) 1067. 